\title{
The pathways from mother's love to baby's future
}

\author{
Aniko Korosi and Tallie Z. Baram* \\ Anatomy/Neurobiology, Pediatrics and Neurology, University of California at Irvine, Irvine, CA, USA
}

Edited by:

Larry J. Young, Emory University School of Medicine, USA; Yerkes National Primate Research Center, USA

\section{Reviewed by:}

Dominique Walker, Douglas Hospital Research Center, Canada

Seema Bhatnagar, Children's Hospital of Philadelphia, USA

Mathias Schmidt, Max Planck Institute of Psychiatry, Germany

*Correspondence:

Tallie Z. Baram, Department of Anatomy/Neurobiology, Pediatrics and Neurology, University of California at Irvine, Med Sci l; ZOT 4475, Irvine, CA 92697-4475, USA.

e-mail: tallie@uci.edu
Together with genetic factors, early-life experience governs the expression and function of stress-related genes throughout life. This, in turn, contributes to either resilience or vulnerability to depression and to aging-related cognitive decline. In humans and animal models, both the quality and quantity of early-life maternal care has been shown to be a predominant signal triggering bi-directional and enduring changes in expression profiles of genes including glucocorticoids and corticotropin releasing factor ( $\mathrm{CRH}$; hypothalamic and hippocampal), associated with the development of resilient or vulnerable phenotypes. However, many crucial questions remain unresolved. For examples, how is the maternal-derived signal transmitted to specific neuronal populations where enduring (likely epigenetic) regulation of gene expression takes place? What is the nature of this information? In other words, how do neurons know to 'turn on' epigenetic machinery? What are the direct functional consequences of altered gene expression? This review describes the voyage of recurrent bursts of sensory input from the mother ('mother's love') to $\mathrm{CRH}$-expressing hypothalamic neurons that govern the magnitude of the response to stress. In addition, the acute and enduring effects of both nurturing and fragmented maternal care on the structure, cellular signaling and function of specific hippocampal and hypothalamic neurons are discussed. The evolving understanding of the processes initiated by the early life experience of 'mother's love' suggest novel molecular targets for prevention and therapy of stress-related affective and cognitive disorders.

Keywords: corticotropin releasing factor (CRH), early life stress, maternal care, epigenetics, hypothalamus, maternal separation, neglect, abuse

\section{EARLY LIFE EXPERIENCE, AND ESPECIALLY SENSORY INPUT FROM THE MOTHER (MATERNAL CARE) LEADS TO ENDURING NEUROPLASTICITY OF NEUROENDOCRINE STRESS RESPONSE AND INFLUENCES COGNITIVE FUNCTION WHY IS THIS TOPIC IMPORTANT? HUMAN PERSPECTIVE AND HISTORY}

Early postnatal life represents a period when the quality of the infant's experience, and specifically of the interaction with the mother, is associated with emotional and cognitive development (Ammerman et al., 1991; Fernald and Gunnar, 2009). The important role of mother-infant interaction as a key determinant of the effects of early-postnatal experience on subsequent mental and cognitive health forms the basis of Bowlby's social attachment theory stating that the mother is the primary social object mediating the effects of the external early environment on the infant (Bowlby, 1982). The maternally mediated changes in the infant's brain (programming) provide a mechanism for changes in the response of the infant to the environment, which last through adulthood. The enduring effects of early life programming may have adaptive and evolutionary advantages for an individual when the "programmed environment" reflects a real-life situation. The 'programming' effect has two facets: Human studies suggest that excellent early-life maternal care is associated with resilience to affective disorders (Gourion et al., 2008). In contrast, adverse early life conditions in infancy, including poverty, substance abuse by the mother or maternal depression, have been associated with fragmented or reduced maternal care, and with vulnerability to psychopathology throughout life (Lupien et al., 2000; Schore, 2000; Agrawal et al., 2001; Repetti et al.,
2002; Halligan et al., 2007), as well as with cognitive decline later in life (Kaplan et al., 2001; Wilson et al., 2007). Among the most influential studies of these effects are those of institutionally reared children, where impoverished care was associated with cognitive and emotional deficits, and these were partially reversible by fostering (Gunnar et al., 2001, 2009; Nelson et al., 2007).

These studies, and numerous additional clinical reports demonstrate a strong association between early life maternal interaction and cognitive function as well as resilience or vulnerability to mood disorders. Therefore, they provide strong impetus to understand the basis for the relationship between early-life experience and subsequent cognitive and emotional health. However, in human studies, causality between early-postnatal experience and long-term outcomes is difficult to infer: some reports are retrospective, introducing recall and other biases, and in prospective longitudinal and cohort studies, the influence of the genetic make-up of individuals on their early-life environment as well as on the predisposition to affective disorders such as depression (Caspi et al., 2003) cannot be excluded.

Therefore, understanding the causal relationship between early experiences including interaction with the mother and life-long cognitive and emotional health benefits from animal models (e.g. Cottrell and Seckl, 2009). These enable prospective longitudinal studies, as well as control of genetic background. In addition, parameters of interest can be manipulated and subsequent experiences can be controlled throughout the entire period of investigation. Finally, direct access to specific brain regions, coupled with 
neuroanatomical, biochemical and genetic approaches can tease out the regions, circuits, mediators and signaling cascades that might contribute to the profound effects of early-life maternal interaction on adult outcome (Joels and Baram, 2009).

\section{HISTORICAL PERSPECTIVE OF WORK IN ANIMAL MODELS}

Over the past half-century there has been a wealth of prospective experiments examining the short and long term consequences of physical and social elements of the early-postnatal environment on the development of stress responses and cognitive functions, with particular focus on the relevance of the mother-infant interaction (Heim et al., 2004). Already the seminal work of Levine (1957) and Denenberg et al. (1967) demonstrated that manipulations of the mother-pup relationship (in rat) have long-term consequences on neuroendocrine and behavioral stress responses of the pups later in life. Initial work on the ontogeny of the stress response suggested that that the first 2 weeks of life in the rodent, the hypothalamic-pituitary-adrenal (HPA) system was relatively unresponsive to stress (termed the stress hyporesponsive period or SHRP); (Schapiro et al., 1962; Schoenfeld et al., 1980; Rosenfeld et al., 1992). However, this was found not to be the case, as immature rats elevated plasma glucocorticoids 300-400\% in response to age-appropriate stressors, (Yi and Baram, 1994; Dent et al., 2000), and human neonatal cortisol increased with stress/pain (Gunnar, 1992). Already in 1977, the observation that mother-pup interaction affected pups' development, led Smothermann to propose the "maternal mediation" hypothesis stating that changes in maternal behavior underlie the effects of early manipulations on the pup (Smotherman et al., 1977). Numerous other studies have been carried out in rodents (Levine and Lewis, 1959; Hess, 1969; Meaney et al., 1996; Avishai-Eliner et al., 2001a; Fenoglio et al., 2005) and primates (Seay and Harlow, 1965; Levine, 1993; Heim et al., 1997; Suomi, 1997), building on these original hypotheses. Throughout these efforts, some of the most useful strategies used to study how altered quality and quantity of mother-pup interaction affects development of stress response and cognitive function long-term have included the 'handling', 'maternal separation' and 'chronic early life stress' paradigms. All of these manipulate specific parameters of maternal care, demonstrating the importance of the maternal factor in the 'programming' of the stress response and subsequent emotional and cognitive functions throughout life, and will be discussed in the next sections.

\section{QUANTITY AS WELL AS QUALITYOF INTERACTIONS OF IMMATURE INDIVIDUALS WITH THEIR MOTHER GOVERN THE RESULTING ADULT PHENOTYPE}

The interaction of the mother with her pups is a complex entity consisting of several aspects, each one impacting the pups' brain in a different manner. In this context, it is helpful to consider this interaction from the perspective of the pup/infant, because the resulting persistent changes take place within specific regions of its brain. For example, a feeding pup receives both nutrition as well as sensory and motor elements derived from the pup's suckling, and contact from the mother (Suchecki et al., 1995; Eghbal-Ahmadi et al., 1999). Studies aiming to dissect out these elements in the regulation of the development of the stress response indicated that different aspects of maternal inputs differentially regulate components of the HPA axis. Sensory stimulation [e.g., licking and grooming (LG) by the dam, as well as suckling motion of the pup] appeared to act directly on corticotropin releasing factor $(\mathrm{CRH})$ - adrenocorticotropin releasing hormone (ACTH) expression and release (Suchecki et al., 1995; Eghbal-Ahmadi et al., 1999). Tactile stimulation is also important in maintaining basal levels of activity of enzymes and hormones necessary for normal growth (Kuhn et al., 1978; Kuhn and Schanberg, 1998). In contrast, nutrition from the mother regulates adrenal function (Suchecki et al., 1995). These original studies have set the stage for experiments where the quantity and quality of specific elements of maternal care were manipulated, enabling analysis of the influence of this variation on infant outcome, as discussed below.

\section{MATERNAL CARE: NATURAL VARIATION AND STRATEGIES FOR ENHANCEMENT OF THIS CARE}

An approach to the question of: 'how does maternal care influence development of the stress response in pups?' is to select mothers based on natural, individual variation in maternal care (e.g. amount of time spent LG and nurturing the pups) and compare the stress response of adults reared by dams exhibiting different level of maternal care. Individual differences in active maternal care in rats and mice were found to be directly associated with differences in stress response in the pups when they reached adulthood (Meaney, 2001; Priebe et al., 2005), such that hormonal stress responses of adults reared by dams exhibiting high levels of LG and arched back nursing were reduced. This was accompanied by reduced CRH expression in the hypothalamus and increased hippocampal glucocorticoid receptor (GR) expression when compared with pups from mothers with low levels of active maternal care (Plotsky and Meaney, 1993; Francis and Meaney, 1999; Meaney, 2001). In addition the adult offspring of high LG mothers exhibited improved hippocampus-dependent cognitive function (Liu et al., 2000) accompanied by longer dendritic branch length and increased spine density in CA1 neurons, alterations in electrophysiological properties at rest and enhanced LTP (Champagne et al., 2008).

The quantity and quality of maternal care can be experimentally manipulated either to enhance or to impair it. Maternal care can be enhanced using the 'handling' procedure. This procedure involves brief ( $15 \mathrm{~min}$ ) daily separation of rat pups from their mother followed by returning the pups to the home cage starting on postnatal day (P) 2 for a minimum of 1 week (Avishai-Eliner et al., 2001a), or up to 3 weeks (Levine and Lewis, 1959; Hess, 1969; Plotsky and Meaney, 1993; Bhatnagar and Meaney, 1995) and has been shown to enhance mother pup interaction by provoking bursts of maternal sensory stimulation of pups immediately after their return to the home cage (Brown et al., 1977; Fenoglio et al., 2006b). Similarly to the adult rats reared by dams that naturally exhibit high levels of care, handling has consistently been found to suppress the stress response during adulthood (Sanchez et al., 2001; Fenoglio et al., 2006b) reduce CRH expression in the hypothalamus, and increase GR in the hippocampus (Plotsky and Meaney, 1993; Avishai-Eliner et al., 2001a). Levels of CRH and CRFR were reduced (Plotsky et al., 2005), and of $\alpha 1$ and $\gamma 2$ subunit of the GABAA receptor were increased in the locus coeruleus (LC). The GABA receptor was also increased in nucleus tractus solitarius, basolateral and 
central nucleus of the amygdala (ACe;) (Caldji et al., 2003). Levels of vasopressin (AVP) were reduced in median eminence (Viau et al., 1993) and found to be either decreased or increased in the hypothalamus (Viau et al., 1993; Todeschin et al., 2009) In addition, adult rats handled early in life were resilient to manipulations that lead to depressive-like behaviors (Meaney et al., 1991) and had improved hippocampus-dependent cognitive function (Meaney et al., 1988; Liu et al., 2000; Tang, 2001; Fenoglio et al., 2005). Together, these studies indicate that either naturally occurring or experimentally enhanced sensory stimulation that pups receive from the dam programs the stress response, leading to blunted HPA axis tone, resilience to manipulations that lead to depressive-like behaviors and improved hippocampus-dependent learning and memory (Korosi and Baram, 2008).

\section{RECURRENT SEPARATION FROM THE MOTHER: RECURRENT EARLY-LIFE STRESS}

In the course of normal mother-pup interactions the dam is regularly away from the nest and pups for periods of 20-30 min (Rosenblatt, 1975). Thus, the handling manipulation does not result in an abnormal period of separation or loss of maternal care. How do longer periods of separation influence the pups' stress response acutely and long-term? Following a single prolonged $(24 \mathrm{~h})$ maternal deprivation, expression of CRH in the PVN was unchanged (Avishai-Eliner et al., 1995; Dent et al., 2000), or reduced (Smith et al., 1997; Workel et al., 2001; Schmidt et al., 2004), and CRFR mRNA expression in the ventromedial hypothalamus was reduced (Eghbal-Ahmadi et al., 1997). The response to stress, measured by ACTH and glucocorticoid levels, were augmented by single prolonged maternal separation (Avishai-Eliner et al., 1995; Dent et al., 2000).

Exposing the animals to recurrent, daily 3-6 h maternal separation during the first 2 weeks of life influenced variably maternal care upon returning the pups to the cage (Pryce et al., 2001; Macri et al., 2004). This recurrent separation augmented the stress response in adult graduates throughout life (Plotsky and Meaney, 1993; Schmidt et al., 2004), but see (Pryce et al., 2001; Lehmann et al., 2002; Giachino et al., 2007), augmented fearfulness in tests of novelty and anxiety (Caldji et al., 1998; Wigger and Neumann, 1999; Ladd et al., 2000) and lead to depressive-like behavior (Ladd et al., 2000; Huot et al., 2002; Aisa et al., 2007). In addition, recurrent maternal separation led to an impaired hippocampus dependent learning and memory later in life (Oitzl et al., 2000; Aisa et al., 2007), as well as to abnormal synaptic plasticity and aberrant expression of the extracellular matrix protein NCAM (Aisa et al., 2009; Bisaz et al., 2009). Molecular changes reported in these recurrently separated rats have included decreased GR binding in both hippocampus and hypothalamus (Plotsky and Meaney, 1993), increased CRH levels in the ACe, LC, and parabrachial nucleus, accompanied by increased CRFR 1 mRNA expression levels in LC and the raphe nucleus (Ladd et al., 1996). Levels of AVP were found either increased or decreased in the hypothalamus and BnST (Desbonnet et al., 2008; Veenema and Neumann, 2009) Together these findings indicate that recurrent prolonged maternal separation leads to increased stress responsiveness both at the molecular and at the behavioral levels during adulthood.

\section{ERRATIC, FRAGMENTED MATERNAL CARE: CHRONIC EARLY-LIFE STRESS}

The studies described so far modulated the quantity of maternal care. In addition, they resulted in acute or recurrent, rather than chronic early-life stress. However, when infants and children are exposed to severe poverty, famine, war or drug-abusing mothers, the stress is typically chronic, and the mother is typically present, but her behavior is abnormal (Whipple and Webster-Stratton, 1991; Koenen et al., 2003; Kendall-Tackett, 2007). A model of chronic early-life stress was developed to recapitulate these important elements of the human condition. Manipulation of the quality of care of a present mother in this model generates chronic (rather than recurrent) early-life 'emotional stress' (Gilles et al., 1996; AvishaiEliner et al., 2001b; Ivy et al., 2008). A hallmark of maternal behavior in neglect/abuse situations is its unpredictable and fragmented quality (Whipple and Webster-Stratton, 1991; Gaudin et al., 1996). The experimental paradigm, consisting of limiting the nesting material available to the dam recreates this pattern both in rat and mouse (Ivy et al., 2008; Rice et al., 2008). The limited nesting material environment results in stress of the mother, promoting fragmented care, i.e., shortened bouts of each nurturing behavior and frequent shifts between behaviors (Ivy et al., 2008; Rice et al., 2008). This aberrant maternal behavior induces chronic early-life stress in the pups, evident from elevated plasma glucocorticoids and increased adrenal weight, often associated with modest, transient reduction of weight gain. At the termination of the 1 -week stress period, $\mathrm{CRH}$ mRNA is reduced in the PVN accompanied by reduced CRHR and GR expression in the hippocampus and unaltered hypothalamic AVP levels (Gilles et al., 1996; Avishai-Eliner et al., 2001b). Whereas these molecular changes are transient, lasting changes are evident in the hippocampus: elevated CRH mRNA levels in CA1 and CA3 (Fenoglio et al., 2006a) and increased numbers of CRHexpressing neurons in both fields (Ivy et al., 2008, Abstract at Society for Neuroscience), as well as dendritic atrophy of pyramidal cells. Importantly, these structural changes are accompanied by profound disruption of LTP in CA1 and CA 3 and impaired hippocampusmediated cognitive impairments, consisting of increased escape latency in the Morris Water maze test and inability to distinguish novel from familiar object in the Object recognition test (Brunson et al., 2005). Thus a period of early-life chronic stress causes acute effects on the stress system and late onset and gradual deterioration of hippocampus mediated learning and memory.

\section{MATERNAL CARE PARAMETERS INFLUENCE CRH mRNA LEVELS ACUTELY, AND MODULATE STRESS RESPONSES AND COGNITIVE FUNCTION LONG-TERM: POTENTIAL MECHANISMS}

Reviewing the diverse manipulations of maternal care discussed above, it becomes evident that both the quality and quantity of maternal care program the stress response and specific cognitive functions in a bi-directional manner: Enhanced maternal care, either as a result of natural variation or via the 'handling' procedure, leads to diminished stress responsiveness and improved cognition. Thus, studies by several groups found augmented performance in the Morris water maze task, as discussed above. Conversely, absence or fragmentation of maternal care results in increased stress responsiveness and progressively impaired cognition commencing in adulthood (see Erratic, Fragmented Maternal Care: Chronic Early-Life Stress). 
It is important to note that while varied maternal care leads to different phenotypes, handling and chronic early life stress both result in reduced $\mathrm{CRH}$ mRNA on P9. What are the potential mechanisms accounting for these differences? How can $\mathrm{CRH}$ mRNA reduction on $\mathrm{P} 9$ be associated with different phenotypes later in life?

The mechanisms accounting for the reduction of hypothalamic CRH mRNA expression after chronic early life stress differs from the early onset and permanent CRH reduction induced by handling, both in the associated neuroendocrine and physiological measures and in the associated phenotype. The reduced CRH levels induced by chronic-early life stress, while apparent immediately at the end of the stress period (P9) is transient in the rat (AvishaiEliner et al., 2001b) and still apparent in the adult mouse (Rice et al., 2008). This reduction of CRH expression is associated with elevated basal CORT, increased adrenal weight, decreased body weight, decreased GR in the hypothalamus and frontal cortex and reduced $\mathrm{CRH}$ receptor binding in the pituitary, all indices of a chronic stress situation (Avishai-Eliner et al., 2001b). The mechanisms underlying $\mathrm{CRH}$ mRNA reduction in this scenario may include altered glucocorticoid negative feedback, as suggested by the elevated glucocorticoids levels and the reduced GR mRNA expression of chronically stressed pups. Alternatively, or in concert, persistent increased CRH release, with limited compensatory enhanced synthesis, leads to depleted mRNA stores of hypothalamic CRH. In contrast to this early-life stress situation, $\mathrm{CRH}$ reduction after augmented maternal care (handling) is not associated with altered basal CORT, ACTH or GR in the hypothalamus, but is the first apparent change in a sequential reduction of hormonal stress response and of increased GR in the hippocampus (Figure 1). This fact suggests that the $\mathrm{CRH}$ reduction in 'handled' pups might be independent of glucocorticoid feedback. In the absence of early alteration in other parameters of the stress system, the onset and persistence of reduced CRH expression might be governed by other mechanisms including epigenetic modulation of the Crh gene.

An important step in understanding long-lasting phenotypes in graduates of varied maternal care is to define how each of these phenotypes arises, i.e., the sequential steps that are involved in its evolution. Therefore, the following sections will describe the brain regions involved in transmission of the maternal-derived 'programming' signals to brain areas involved in the stress response, and the molecules involved in initiating and maintaining the phenotype. We will focus on the phenotype induced by augmented maternal care (handling), which provides resilience to depression and enhanced cognitive function.

\section{MOLECULAR MECHANISM RESPONSIBLE FOR THE ENDURING EFFECTS OF MATERNAL CARE (PROGRAMMING) SEOUENCE OF MOLECULAR CHANGES IN THE INFANT'S BRAIN}

Persistently altered mRNA expression levels of GR in hippocampus, and of the $\mathrm{CRH}$ in hypothalamic neurons have been established as key elements of the handling-induced programming (Plotsky and Meaney, 1993; Avishai-Eliner et al., 2001a). Specifically, GR expression levels in the hippocampus were elevated, whereas CRH mRNA levels in the hypothalamus were reduced. Discovering which of these fundamental changes occurred first should help in identifying the location and nature of the initial 'programming' steps triggered by the early life experience. The set-point and magnitude of the hormonal responses to stress are under tight and intricate regulation (Walker and Dallman, 1993) and are influenced by both hippocampal GR and hypothalamic $\mathrm{CRH}$ function. What is the precise timing and sequence of the handling-induced alterations? Increased GR expression has been proposed as an early and critical effect of the enriched sensory input (Meaney et al., 1996; Liu et al., 1997; Francis et al., 1999; Kaffman and Meaney, 2007). The increased GR levels would then transmit more efficiently negative glucocorticoid feedback to the HPA axis, downregulating hypothalamic CRH and the subsequent responses to stress. However programming of $\mathrm{Crh}$ gene expression in PVN neurons to lower levels has been found to take place already by the end of the daily week-long handling period (P9), followed by attenuated hormonal responses to stress and enduring enhancement of hippocampal GR expression, which take place by $\mathrm{P} 23$ and between $\mathrm{P} 23$ and $\mathrm{P} 45$ respectively (AvishaiEliner et al., 2001a; Figure 1). These findings establish that modulation of $\mathrm{CRH}$ expression precedes the increased GR expression, indicating that programming of the levels of Crh gene expression is an early and potentially key step in the mechanism of maternalcare induced stress-resilient phenotype. This supposition predicts

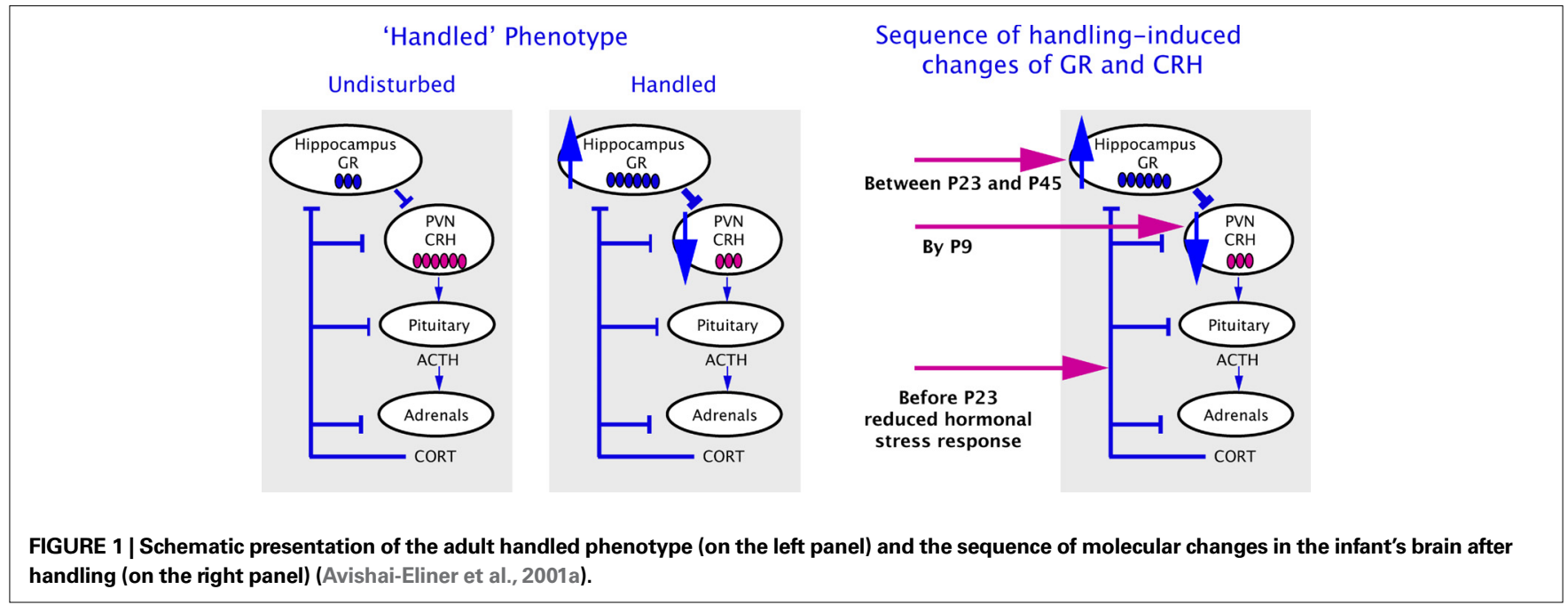


that genetic variants or mutations of $\mathrm{CRH}$ or its receptors would confer similar phenotypes. In line with this supposition, it has been recently reported that specific polymorphism of CRHR moderates the effects of early-life stress on adult psychopathology. The presence of several single nucleotide polymorphisms (SNPs) in the Crhrl gene interacted with childhood maltreatment to predict depressive symptoms (Bradley et al., 2008). A haplotype including a specific combination of the SNPs was protective against depressive symptoms among maltreated subjects (Bradley et al., 2008) and moderated the effect of childhood maltreatment on cortisol responses to the Dexhamethasone/CRH test (Tyrka et al., 2009).

\section{NEURONAL PATHWAYS INVOLVED IN TRANSMITTING THE SENSORY INPUT (MATERNAL CARE) FROM MOTHER TO PUPS, AND WITHIN THE PUP'S BRAIN TO THE 'PROGRAMMED' REGIONS}

If the initial consequences of the augmented maternal-derived sensory input is to change $\mathrm{CRH}$ expression levels in the PVN, then we need to understand how the maternal signal reaches this brain region, and more specifically, the parvocellular $\mathrm{CRH}$-expressing neurons in the PVN. Using the immediate-early gene Fos to visualize neurons activated by maternal-derived sensory signals, a pathway regulating the hypothalamic PVN emerged: Fos expression was induced in the bed nucleus of the stria terminalis (BnST) and the ACe after a single day of handling (Fenoglio et al., 2006b), and both these regions generally augment CRH expression in PVN (Feldman et al., 1994; Akana and Dallman, 1997). In contrast, repeated handling induced Fos expression also in the thalamic paraventricular nucleus (PVT), a region with major inhibitory output onto ACe (Bhatnagar and Dallman, 1998; Spencer et al., 2004), and thus on the PVN. The activation of PVT neurons after recurrent handling likely altered their firing rate and/or neurotransmitter release, altering the combinatorial afferent information arriving at $\mathrm{CRH}$-expressing neurons in PVN (Figure 2). Indeed, PVT has been proposed previously as a region involved in processing the 'memory' of experiences related to the stress-response system (Bhatnagar and Dallman, 1998; Bell et al., 2000; Jaferi and Bhatnagar, 2006). In addition recurrent daily handling was required for reduced hypothalamic $\mathrm{CRH}$ expression (Fenoglio et al., 2006b), because a single day of increased maternal care did not result in altered expression of CRH in the PVN. Together with the patterns of fos-expression described above, these findings suggest that a key distinguishing feature of the signal that 'programs' CRH expression at lower levels is the recurrence of this signal (Fenoglio et al., 2006b; Korosi and Baram, 2008).

\section{WHAT TYPE OF INFORMATION REACHES THE HYPOTHALAMIC CRH NEURONS, 'COMMANDING' IT TO REPRESS CRH EXPRESSION PERSISTENTLY?}

What is the nature of the signal, derived from maternal-derived sensory experience, which reaches the CRH neuron and results in persistently reduced expression of the Crh gene? The hypothalamic $\mathrm{CRH}$ neuron is the target of a neuronal network, activated by barrages of maternal care induced by the brief daily separation of rat pups from the dam (Fenoglio et al., 2006b), and upon recurrence of this activation, the PVT is recruited, providing an inhibitory signal to the PVN. We therefore examined directly the excitatory and inhibitory afferent input onto the $\mathrm{CRH}$ neuron, and found that augmented early-life experience reduced excitatory synaptic input onto the $\mathrm{CRH}$ neuron (A. Korosi et al., in review). This reduced excitation, evident as reduced synapse number and function, should influence intracellular signaling cascades resulting in suppressed CRH expression (see next section).

\section{MOLECULAR CASCADES INVOLVED IN PROGRAMMING THE INFANT BRAIN}

Because the handling-evoked maternal sensory stimulation elicits a signal that provokes repression of CRH expression in PVN neurons, it is reasonable to query whether signalling cascade and transcription factors involved in the regulation of $\mathrm{CRH}$ expression were altered in these cells. Phosphorylation of cAMP response elementbinding protein (CREB) and ERK influence the initial activation of the critical CRE domain on the Crh gene promoter (Seasholtz et al., 1988). In addition, phosphorylation of the transcription factor ERK (pERK) is crucial for maintaining CREB phosphorylated beyond the first seconds after synaptic activation, contributing to plasticity at longer timescale (West et al., 2002). CREB and ERK are ubiquitously phosphorylated in the PVN of undisturbed P9 rats and can therefore be candidates for deactivation by inhibitory inputs evoked by handling. In fact a strong decrease in the number of pERK immunoreactive cells in the PVN was found in rats handled recurrently (Fenoglio et al., 2006b). Accordingly, transcription

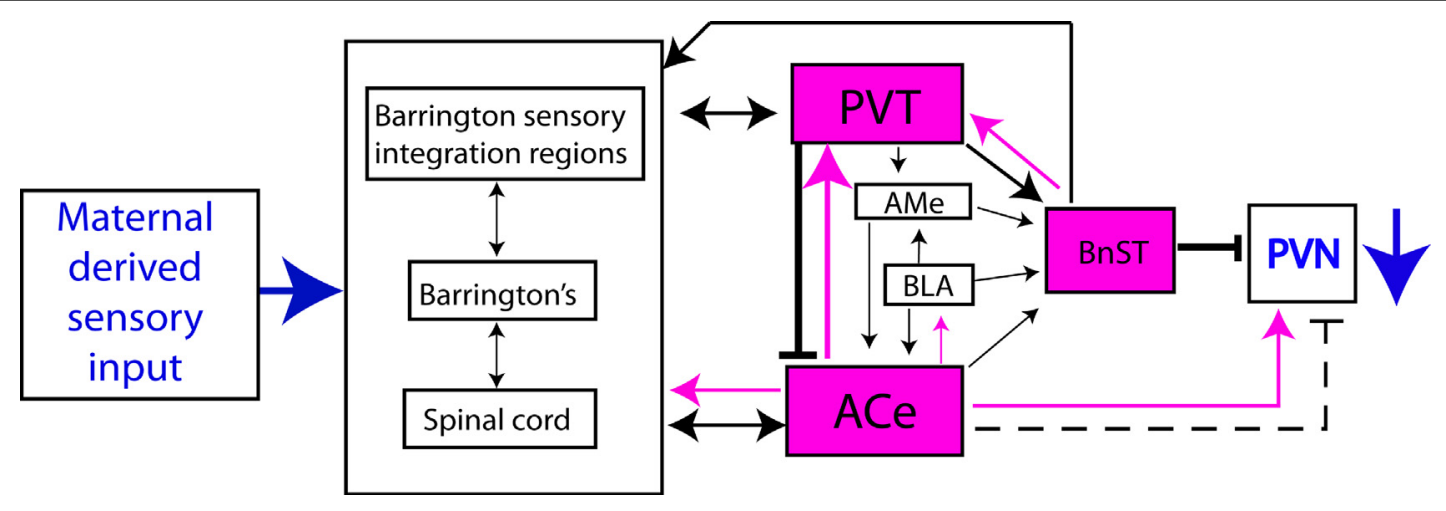

FIGURE 2 | Brain regions activated by maternal-derived sensory input (in fuchsia), and their relationship to the expression of CRH in PVN. The red arrow indicates excitatory input to PVN after single handling, and the blunt black arrows show the inhibitory consequences of activation of PVT after recurrent handling. 
of $\mathrm{Crh}$ gene (measured by CRH hnRNA) in response to separation stress decreased in PVN of recurrently handled pups (Fenoglio et al., 2006b). This reduced transcription of the Crh gene should result in reduced steady state $\mathrm{CRH}$ mRNA levels, as indeed observed in handled rats throughout their lives.

\section{TRANSLATIONAL AND THERAPEUTIC IMPLICATIONS OF THE PROGRAMMING EFFECTS OF MATERNAL CARE ON THE STRESS SYSTEM}

Can we recreate the salubrious consequences of augmented maternal care for improving human health? Is there a critical time window for these effects? The sequence of changes described above suggests that reduced $\mathrm{CRH}$ levels might be a key initial target of augmented maternal care. Reduced expression of $\mathrm{CRH}$, in turn, will promote less peptide release in response to stress and thus diminished activation of CRH receptors in the pituitary and a resulting reduction in plasma glucocorticoids levels. This reduction should promote up-regulation of GR expression. If reduced activation of CRF by $\mathrm{CRH}$ (and consequent lower stress-evoked plasma glucocorticoid levels) is required for long-lasting up-regulation of GR expression in the hippocampus and improved learning and memory functions,

\section{REFERENCES}

Agrawal, A. F., Brodie, E. D., III, and Brown, J. (2001). Parent-offspring coadaptation and the dual genetic control of maternal care. Science 292, 1710-1712.

Aisa, B., Elizalde, N., Tordera, R., Lasheras, B., Del Rio, J., and Ramirez, M. J. (2009). Effects of neonatal stress on markers of synaptic plasticity in the hippocampus: implications for spatial memory. Hippocampus. [Epub ahead of print].

Aisa, B., Tordera, R., Lasheras, B., Del Rio, J., and Ramirez, M. J. (2007). Cognitive impairment associated to HPA axis hyperactivity after maternal separation in rats. Psychoneuroendocrinology 32, 256-266.

Akana, S. F., and Dallman, M. F. (1997). Chronic cold in adrenalectomized, corticosterone (B)-treated rats: facilitated corticotropin responses to acute restraint emerge as B increases. Endocrinology 138, 3249-3258.

Ammerman, R. T., Van Hasselt, V. B., and Hersen, M. (1991). Parent-child problem-solving interactions in families of visually impaired youth. J. Pediatr. Psychol. 16, 87-101.

Avishai-Eliner, S., Eghbal-Ahmadi, M., Tabachnik, E., Brunson, K. L., and Baram,T.Z. (2001a).Down-regulation of hypothalamic corticotropinreleasing hormone messenger ribonucleic acid (mRNA) precedes early-life experience-induced changes in hippocampal glucocorticoid receptor mRNA. Endocrinology 142, 89-97.

Avishai-Eliner, S., Gilles, E. E., Eghbal-Ahmadi, M., Bar-El, Y., and Baram, T. Z. (2001b). Altered regulation of gene and protein expression of hypothalamic-pituitaryadrenal axis components in an immature rat model of chronic stress. J. Neuroendocrinol. 13, 799-807.

Avishai-Eliner, S., Yi, S. J., Newth, C. J., and Baram, T. Z. (1995). Effects of maternal and sibling deprivation on basal and stress induced hypothalamicpituitary-adrenal components in the infant rat. Neurosci. Lett. 192, 49-52.

Bell, M. E., Bhatnagar, S., Akana, S. F., Choi, S., and Dallman, M. F. (2000). Disruption of arcuate/paraventricular nucleus connections changes body energy balance and response to acute stress. J. Neurosci. 20, 6707-6713.

Bhatnagar, S., and Dallman, M. (1998). Neuroanatomical basis for facilitation of hypothalamic-pituitary-adrenal responses to a novel stressor after chronic stress. Neuroscience 84, 1025-1039.

Bhatnagar, S., and Meaney, M. J. (1995). Hypothalamic-pituitary-adrenal function in chronic intermittently cold-stressed neonatally handled and non handled rats. J. Neuroendocrinol. 7, 97-108.

Bisaz, R., Conboy, L., and Sandi, C. (2009). Learning under stress: a role for the neural cell adhesion molecule NCAM. Neurobiol. Learn. Mem. 91, 333-342.

Bowlby, J. (1982). Attachment and loss: retrospect and prospect. Am. J. Orthopsychiatry 52, 664-678.

Bradley, R. G., Binder, E. B., Epstein, M. P., Tang, Y., Nair, H. P., Liu, W., Gillespie, C. F., Berg, T., Evces, M., Newport, D. J., Stowe, Z. N., Heim, C. M., Nemeroff, C. B., Schwartz, A., Cubells, J. F., and

then partially blocking $\mathrm{CRF}_{1}$ receptors in undisturbed rats should recapitulate these changes. Indeed reducing $\mathrm{CRH}-\mathrm{CRH}$-receptor signalling by a systemic, post hoc administration of $\mathrm{CRF}_{1}$ antagonist in immature rats, that did not receive augmented maternal care, from $\mathrm{P} 10-17$ was sufficient to upregulate hippocampal GR persistently and to confer the behavioral 'phenotype' of improved cognitive functions induced by augmented maternal care (Fenoglio et al., 2005). Thus, the enduring effects of enhanced early-life maternal care in handled rats on hippocampal GR gene expression, $\mathrm{CRH}$ mRNA in the PVN, and learning and memory are recapitulated by post hoc partial blockade of CRF1 receptor in undisturbed animals. These results support the idea that programming of the levels of Crh gene expression is a key and early step in the cellular and molecular cascades by which enhanced maternal care 'programs' stress responses and enhances cognitive function long-term, and position CRH-CRH-receptor intersection as molecular targets for influencing emotional and cognitive function after adverse earlylife experience.

\section{ACKNOWLEDGMENTS}

This work was supported by NIH NS28912 and MH73136.

Ressler, K. J. (2008). Influence of child abuse on adult depression: moderation by the corticotropin-releasing hormone receptor gene. Arch. Gen. Psychiatry 65, 190-200.

Brown, C. P., Smotherman, W. P., and Levine, S. (1977). Interactioninduced reduction in differential maternal responsiveness: an effect of cue-reduction or behavior? Dev Psychobiol. 10, 273-280.

Brunson, K. L., Kramar,E.,Lin, B., Chen, Y. Colgin, L. L., Yanagihara, T. K. Lynch, G., and Baram, T. Z. (2005). Mechanisms of late-onset cognitive decline after early-life stress. J. Neurosci. 25, 9328-9338.

Caldji, C., Diorio, J., and Meaney, M. J. (2003). Variations in maternal care alter $\operatorname{GABA}(\mathrm{A})$ receptor subunit expression in brain regions associated with fear. Neuropsychopharmacology 28, 1950-1959.

Caldji, C., Tannenbaum, B., Sharma, S Francis, D., Plotsky, P. M., and Meaney, M. J. (1998). Maternal care during infancy regulates the development of neural systems mediating the expression of fearfulness in the rat. Proc. Natl. Acad. Sci. U.S.A. 95 5335-5340.

Caspi, A., Sugden, K., Moffitt, T. E. Taylor, A., Craig, I. W., Harrington, H., McClay, J., Mill, J., Martin, J., Braithwaite, A., and Poulton, R. (2003). Influence of life stress on depression: moderation by a polymorphism in the 5-HTT gene. Science 301, 386-389.

Champagne, D. L., Bagot, R. C., van Hasselt, F., Ramakers, G., Meaney, M. J., de Kloet, E. R., Joels, M., and Krugers, H. (2008). Maternal care and hippocampal plasticity: evidence for experience-dependent structural plasticity, altered synaptic functioning, and differential responsiveness to glucocorticoids and stress. J. Neurosci. 28, 6037-6045.

Cottrell, E. C., and Seckl, J. R. (2009). Prenatal stress, glucocorticoids and the programming of adult disease. Front. Behav. Neurosci. 3. doi: 10.3389/neuro.08.019.2009.

Denenberg, V. H., Brumaghim, J. T., Haltmeyer, G. C., and Zarrow, M. X. (1967). Increased adrenocortical activity in the neonatal rat following handling. Endocrinology 81, 1047-1052.

Dent, G. W., Smith, M. A., and Levine, S. (2000). Rapid induction of corticotropin-releasing hormone gene transcription in the paraventricular nucleus of the developing rat. Endocrinology 141, 1593-1598.

Desbonnet, L., Garrett, L., Daly, E., McDermott, K. W., and Dinan, T. G. (2008). Sexually dimorphic effects of maternal separation stress on corticotrophin-releasing factor and vasopressin systems in the adult rat brain. Int. J. Dev. Neurosci. 26, 259-268.

Eghbal-Ahmadi, M., Avishai-Eliner, S. Hatalski, C. G., and Baram, T.Z. (1999). Differential regulation of the expression of corticotropin-releasing factor receptor type 2 (CRF2) in hypothalamus and amygdala of the immature rat by sensory input and food intake. J. Neurosci. 19, 3982-3991.

Eghbal-Ahmadi, M., Hatalski, C. G., Avishai-Eliner, S., and Baram, T. Z. (1997). Corticotropin releasing factor receptor type II (CRF2) mes- 
senger ribonucleic acid levels in the hypothalamic ventromedial nucleus of the infant rat are reduced by maternal deprivation. Endocrinology 138, 5048-5051.

Feldman, S., Conforti, N., Itzik, A., and Weidenfeld, J. (1994). Differential effect of amygdaloid lesions on CRF-41, ACTH and corticosterone responses following neural stimuli. Brain Res. 658, 21-26.

Fenoglio, K. A., Brunson, K. L., AvishaiEliner, S., Stone, B. A., Kapadia, B. J., and Baram, T. Z. (2005). Enduring, handling-evoked enhancement of hippocampal memory function and glucocorticoid receptor expression involves activation of the corticotropinreleasing factor type 1 receptor. Endocrinology 146, 4090-4096.

Fenoglio, K. A., Brunson, K. L., and Baram, T. Z. (2006a). Hippocampal neuroplasticity induced by early-life stress:functional and molecular aspects. Front. Neuroendocrinol. 27, 180-192. doi: 10.1016/j.yfrne.2006.02.001

Fenoglio, K. A., Chen, Y., and Baram, T. Z. (2006b). Neuroplasticity of the hypothalamic-pituitary-adrenal axis early in life requires recurrent recruitment of stress-regulating brain regions. J. Neurosci. 26, 2434-2442.

Fernald, L. C., and Gunnar, M. R. (2009). Poverty-alleviation program participation and salivary cortisol in very low-income children. Soc. Sci. Med. 68, 2180-2189.

Francis, D., Diorio, J., Liu, D., and Meaney, M. J. (1999). Nongenomic transmission across generations of maternal behavior and stress responses in the rat. Science 286, 1155-1158.

Francis, D. D., and Meaney, M. J. (1999). Maternal care and the development of stress responses. Curr. Opin. Neurobiol. 9, 128-134.

Gaudin, J. M., Jr., Polansky, N. A., Kilpatrick,A.C., and Shilton, P. (1996). Family functioning in neglectful families. Child Abuse Negl. 20, 363-377.

Giachino, C., Canalia, N., Capone, F., Fasolo, A., Alleva, E., Riva, M. A., Cirulli, F., and Peretto, P. (2007). Maternal deprivation and early handling affect density of calcium binding protein-containing neurons in selected brain regions and emotional behavior in periadolescent rats. Neuroscience 145, 568-578.

Gilles, E. E., Schultz, L., and Baram, T. Z. (1996). Abnormal corticosterone regulation in an immature rat model of continuous chronic stress. Pediatr. Neurol. 15, 114-119.

Gourion, D., Arseneault, L., Vitaro, F., Brezo, J., Turecki, G., and Tremblay, R. E. (2008). Early environment and major depression in young adults: a longitudinal study. Psychiatry Res. 161, 170-176.

Gunnar, M. R. (1992). Reactivity of the hypothalamic-pituitaryadrenocortical system to stressors in normal infants and children. Pediatrics 90, 491-497.

Gunnar, M. R., Frenn, K., Wewerka, S. S., and Van Ryzin, M. J. (2009). Moderate versus severe early life stress: associations with stress reactivity and regulation in 10-12-year-old children. Psychoneuroendocrinology 34, 62-75.

Gunnar,M.R.,Morison, S.J., Chisholm, K. and Schuder, M. (2001). Salivary cortisol levels in children adopted from romanian orphanages. Dev. Psychopathol. 13, 611-628.

Halligan, S. L., Herbert, J., Goodyer, I., and Murray, L. (2007). Disturbances in morning cortisol secretion in association with maternal postnatal depression predict subsequent depressive symptomatology in adolescents. Biol. Psychiatry 62, 40-46.

Heim, C., Owens, M. J., Plotsky, P. M., and Nemeroff, C. B. (1997). The role of early adverse life events in the etiology of depression and posttraumatic stress disorder. Focus on corticotropinreleasing factor. Ann. N. Y. Acad. Sci. 821, 194-207.

Heim,C.,Plotsky,P.M.,andNemeroff, C. B. (2004). Importance of studying the contributions of early adverse experience to neurobiological findings in depression. Neuropsychopharmacology 29, 641-648.

Hess, G. (1969). Perception of nursing role in a developing mental health center. J. Psychiatr. Nurs. Ment. Health Serv. 7, 77-81.

Huot, R. L., Plotsky, P. M., Lenox, R. H., and McNamara, R. K. (2002). Neonatal maternal separation reduces hippocampal mossy fiber density in adult Long Evans rats. Brain Res. 950, 52-63.

Ivy, A.S., Brunson, K. L., Sandman, C., and Baram, T. Z. (2008). Dysfunctional nurturing behavior in rat dams with limited access to nesting material: a clinically relevant model for early-life stress. Neuroscience 154, 1132-1142.

Jaferi, A., and Bhatnagar, S. (2006). Corticosterone can act at the posterior paraventricular thalamus to inhibit hypothalamic-pituitary-adrenal activity in animals that habituate to repeated stress. Endocrinology 147, 4917-4930.

Joels, M., and Baram, T. Z. (2009). The neuro-symphony of stress. Nat. Rev. Neurosci. 10, 459-466.

Kaffman, A., and Meaney, M. J. (2007). Neurodevelopmental sequelae of postnatal maternal care in rodents: clinical and research implications of molecular insights. J. Child Psychol. Psychiatry 48, 224-244.
Kaplan, G. A., Turrell, G., Lynch, J. W., Everson, S. A., Helkala, E. L., and Salonen, J. T. (2001). Childhood socioeconomic position and cognitive function in adulthood. Int. J. Epidemiol. 30, 256-263.

Kendall-Tackett, K. A. (2007). Violence against women and the perinatal period: the impact of lifetime violence and abuse on pregnancy, postpartum, and breastfeeding. Trauma Violence Abuse 8, 344-353.

Koenen, K. C., Moffitt, T. E., Caspi, A., Taylor, A., and Purcell, S. (2003). Domestic violence is associated with environmental suppression of IQ in young children. Dev. Psychopathol. 15, 297-311.

Korosi, A., and Baram, T. Z. (2008). The central corticotropin releasing factor system during development and adulthood. Eur. J. Pharmacol. 583, 204-214.

Kuhn, C. M., Butler, S. R., and Schanberg, S. M. (1978). Selective depression of serum growth hormone during maternal deprivation in rat pups. Science 201, 1034-1036.

Kuhn, C. M., and Schanberg, S. M. (1998). Responses to maternal separation: mechanisms and mediators. Int. J. Dev Neurosci. 16, 261-270.

Ladd,C.O.,Huot,R.L., Thrivikraman, K. V. Nemeroff, C. B., Meaney, M. J., and Plotsky, P. M. (2000). Long-term behavioral and neuroendocrine adaptations to adverse early experience. Prog. Brain Res. 122, 81-103.

Ladd, C. O., Owens, M. J., and Nemeroff, C. B. (1996). Persistent changes in corticotropin-releasing factor neuronal systems induced by maternal deprivation. Endocrinology 137, 1212-1218.

Lehmann, J., Pryce, C. R., JongenRelo, A. L., Stohr, T., Pothuizen, H.H., and Feldon, J. (2002). Comparison of maternal separation and early handling in terms of their neurobehavioral effects in aged rats. Neurobiol. Aging 23, 457-466.

Levine, S. (1957). Infantile experience and resistance to physiological stress. Science 126, 405.

Levine, S. (1993). The psychoendocrinology of stress. Ann. N. Y. Acad. Sci. 697, 61-69.

Levine, S., and Lewis, G. W. (1959). The relative importance of experimenter contact in an effect produced by extra-stimulation in infancy. J. Comp. Physiol. Psychol. 52, 368-369.

Liu, D., Diorio, J., Day, J. C., Francis, D. D. and Meaney, M. J. (2000). Maternal care, hippocampal synaptogenesis and cognitive development in rats. Nat. Neurosci. 3, 799-806.

Liu, D., Diorio, J., Tannenbaum, B., Caldji, C., Francis, D., Freedman, A.,
Sharma, S., Pearson, D., Plotsky, P. M., and Meaney, M. J. (1997). Maternal care, hippocampal glucocorticoid receptors, and hypothalamicpituitary-adrenal responses to stress. Science 277, 1659-1662.

Lupien, S. J., King, S., Meaney, M. J., and McEwen, B. S. (2000). Child's stress hormone levels correlate with mother's socioeconomic status and depressive state. Biol. Psychiatry 48, 976-980.

Macri, S., Mason, G. J., and Wurbel, H. (2004). Dissociation in the effects of neonatal maternal separations on maternal care and the offspring's HPA and fear responses in rats. Eur. J. Neurosci. 20, 1017-1024.

Meaney, M. J. (2001). Maternal care, gene expression, and the transmission of individual differences in stress reactivity across generations. Annu. Rev. Neurosci. 24, 1161-1192.

Meaney, M. J.,Aitken, D. H., van Berkel, C., Bhatnagar, S., and Sapolsky, R. M. (1988). Effect of neonatal handling on age-related impairments associated with the hippocampus. Science 239, 766-768.

Meaney, M. J., Diorio, J., Francis, D., Widdowson, J., LaPlante, P. Caldji, C., Sharma, S., Seckl, J. R., and Plotsky, P. M. (1996). Early environmental regulation of forebrain glucocorticoid receptor gene expression: implications for adrenocortical responses to stress. Dev. Neurosci. 18, 49-72.

Meaney, M. J., Viau, V., Bhatnagar, S., Betito, K., Iny, L. J., O’Donnell, D., and Mitchell, J. B. (1991). Cellular mechanisms underlying the development and expression of individual differences in the hypothalamic-pituitaryadrenal stress response. J. Steroid Biochem. Mol. Biol. 39, 265-274.

Nelson, C.A., III,Zeanah, C. H., Fox, N. A., Marshall, P. J., Smyke, A. T., and Guthrie, D. (2007). Cognitive recovery in socially deprived young children: the Bucharest Early Intervention Project. Science 318, 1937-1940.

Oitzl, M. S., Workel, J. O., Fluttert, M., Frosch, F., and De Kloet, E. R. (2000). Maternal deprivation affects behaviour from youth to senescence: amplification of individual differences in spatial learning and memory in senescent Brown Norway rats. Eur. J. Neurosci. 12, 3771-3780.

Plotsky, P. M., and Meaney, M. J. (1993). Early, postnatal experience alters hypothalamic corticotropin-releasing factor (CRF) mRNA, median eminence CRF content and stress-induced release in adult rats. Brain. Res. Mol. Brain Res. 18, 195-200.

Plotsky, P. M., Thrivikraman, K. V., Nemeroff, C. B., Caldji, C., Sharma, S., 
and Meaney, M. J. (2005). Long-term consequences of neonatal rearing on central corticotropin-releasing factor systems in adult male rat offspring. Neuropsychopharmacology 30, 2192-2204.

Priebe, K., Romeo, R. D., Francis, D. D., Sisti, H. M., Mueller, A., McEwen, B. S., and Brake, W. G. (2005). Maternal influences on adult stress and anxietylike behavior in C57BL/6J and BALB/ cJ mice: a cross-fostering study. Dev. Psychobiol. 47, 398-407.

Pryce, C. R., Bettschen, D., and Feldon, J. (2001). Comparison of the effects of early handling and early deprivation on maternal care in the rat. Dev. Psychobiol. 38, 239-251.

Repetti,R.L., Taylor,S.E., and Seeman, T. E. (2002). Risky families: family social environments and the mental and physical health of offspring. Psychol. Bull. 128, 330-366.

Rice, C. J., Sandman, C. A., Lenjavi, M. R., and Baram, T. Z. (2008). A novel mouse model for acute and longlasting consequences of early life stress. Endocrinology 149, 4892-4900.

Rosenblatt, J. S. (1975). Prepartum and postpartum regulation of maternal behaviour in the rat. Ciba Found. Symp. 33, 17-37.

Rosenfeld, P., Suchecki, D., and Levine, S. (1992). Multifactorial regulation of the hypothalamic-pituitary-adrenal axis during development. Neurosci. Biobehav. Rev. 16, 553-568.

Sanchez, M. M., Ladd, C. O., and Plotsky, P. M. (2001). Early adverse experience as a developmental risk factor for later psychopathology: evidence from rodent and primate models. Dev. Psychopathol. 13, 419-449.

Schapiro, S., Geller, E., and Eiduson, S. (1962). Neonatal adrenal cortical response to stress and vasopressin. Proc. Soc. Exp. Biol. Med. 109, 937-941.

Schmidt, M., Enthoven, L., van Woezik, J. H., Levine, S., de Kloet, E. R., and Oitzl, M. S. (2004). The dynamics of the hypothalamic-pituitary-adrenal axis during maternal deprivation. J. Neuroendocrinol. 16, 52-57.

Schoenfeld, N. M., Leathem, J. H., and Rabii, J. (1980). Maturation of adrenal stress responsiveness in the rat. Neuroendocrinology 31, 101-105.

Schore, A. N. (2000). Attachment and the regulation of the right brain. Attach. Hum. Dev. 2, 23-47.

Seasholtz, A. F., Thompson, R. C., and Douglass, J. O. (1988). Identification of a cyclic adenosine monophosphateresponsive element in the rat corticotropin-releasing hormone gene. Mol. Endocrinol. 2, 1311-1319.

Seay, B., and Harlow, H.F.(1965). Maternal separation in the rhesus monkey. J. Nerv. Ment. Dis. 140, 434-441.

Smith, M. A., Kim, S. Y., van Oers, H. J., and Levine, S. (1997). Maternal deprivation and stress induce immediate early genes in the infant rat brain. Endocrinology 138, 4622-4628.

Smotherman, W. P., Brown, C. P., and Levine, S. (1977). Maternal responsiveness following differential pup treatment and mother-pup interactions. Horm. Behav. 8, 242-253.

Spencer,S.J., Fox, J.C., and Day, T.A. (2004). Thalamic paraventricular nucleus lesions facilitate central amygdala neuronal responses to acute psychological stress. Brain Res. 997, 234-237.

Suchecki, D., Nelson, D. Y., Van Oers, H., and Levine, S. (1995). Activation and inhibition of the hypothalamicpituitary-adrenal axis of the neonatal rat: effects of maternal deprivation. Psychoneuroendocrinology 20 , 169-182.

Suomi, S. J. (1997). Early determinants of behaviour: evidence from primate studies. Br. Med. Bull. 53, 170-184.

Tang, A. C. (2001). Neonatal exposure to novel environment enhances hippocampal-dependent memory function during infancy and adulthood. Learn. Mem. 8, 257-264.
Todeschin,A.S.,Winkelmann-Duarte, E. C. Jacob, M. H., Aranda, B. C., Jacobs, S. Fernandes, M. C., Ribeiro, M. F. Sanvitto, G. L., and Lucion, A. B. (2009). Effects of neonatal handling on social memory, social interaction, and number of oxytocin and vasopressin neurons in rats. Horm. Behav. 56, 93-100.

Tyrka, A. R., Price, L. H., Gelernter, J., Schepker, C., Anderson, G. M., and Carpenter, L. L. (2009). Interaction of childhood maltreatment with the corticotropin-releasing hormone receptor gene: effects on hypothalamicpituitary-adrenal axis reactivity. Biol. Psychiatry. [Epub ahead of print].

Veenema, A. H., and Neumann, I. D (2009). Maternal separation enhances offensive play-fighting, basal corticosterone and hypothalamic vasopressin mRNA expression in juvenile male rats. Psychoneuroendocrinology 34 463-467.

Viau, V., Sharma, S., Plotsky, P. M., and Meaney, M. J. (1993). Increased plasma ACTH responses to stress in nonhandled compared with handled rats require basal levels of corticosterone and are associated with increased levels of ACTH secretagogues in the median eminence. J. Neurosci. 13 1097-1105.

Walker, C. D., and Dallman, M. F. (1993) Neonatal facilitation of stress-induced adrenocorticotropin secretion by prior stress: evidence for increased central drive to the pituitary. Endocrinology 132, 1101-1107.

West, A. E., Griffith, E. C., and Greenberg, M. E. (2002). Regulation of transcription factors by neuronal activity. Nat. Rev. Neurosci. 3 , 921-931.

Whipple, E. E., and Webster-Stratton, C. (1991). The role of parental stress in physically abusive families. Child Abuse Negl. 15, 279-291.

Wigger, A., and Neumann, I. D. (1999) Periodic maternal deprivation induces gender-dependent alterations in behavioral and neuroendocrine responses to emotional stress in adult rats. Physiol. Behav. 66, 293-302.

Wilson, R. S., Schneider, J. A., Boyle, P. A., Arnold, S. E., Tang, Y., and Bennett, D. A. (2007). Chronic distress and incidence of mild cognitive impairment. Neurology 68, 2085-2092.

Workel, J. O., Oitzl, M. S., Fluttert, M., Lesscher, H., Karssen, A., and de Kloet, E. R. (2001). Differential and age-dependent effects of maternal deprivation on the hypothalamicpituitary-adrenal axis of brown norway rats from youth to senescence. J. Neuroendocrinol. 13, 569-580.

Yi, S. J., and Baram, T. Z. (1994). Corticotropin-releasing hormone mediates the response to cold stress in the neonatal rat without compensatory enhancement of the peptide's gene expression. Endocrinology 135, 2364-2368.

Conflict of Interest Statement: The authors declare that the research was conducted in the absence of any commercial or financial relationships that could be construed as a potential conflict of interest.

Received: 30 May 2009; paper pending published: 17 June 2009; accepted: 20 August 2009; published online: 24 September 2009.

Citation: Korosi A and Baram TZ (2009) The pathways from mother's love to baby's future. Front. Behav. Neurosci. 3:27. doi: 10.3389/neuro.08.027.2009

Copyright (c) 2009 Korosi and Baram. This is an open-access article subject to an exclusive license agreement between the authors and the Frontiers Research Foundation, which permits unrestricted use, distribution, and reproduction in any medium, provided the original authors and source are credited. 